\title{
Comparison of Double-Lumen Tube and EZ-Blocker for Lung Separation in Thoracic Surgery - A Randomised Controlled Clinical Trial
}

Joachim Risse

University Hospital Essen

Karsten Szeder

Philipps-University Marburg

Ann-Kristin Schubert

Philipps-University Marburg

Thomas Wiesmann

Philipps-University Marburg

Hanns-Christian Dinges

Philipps-University Marburg

Carsten Feldmann

Philipps-University Marburg

Hinnerk Wulf

Philipps-University Marburg

Karl Matteo Meggiolaro ( $\sim$ meggiola@med.uni-marburg.de )

Philipps-University Marburg

\section{Research Article}

Keywords: EZ-bronchial blocker, DLT-Intubation, Lung separation, Thoracic anesthesia

Posted Date: August 5th, 2021

DOl: https://doi.org/10.21203/rs.3.rs-599775/v1

License: (c) (1) This work is licensed under a Creative Commons Attribution 4.0 International License. Read Full License 


\section{Abstract}

\section{Background:}

Double lumen tube (DLT) intubation is the most commonly used technique for lung separation. Bronchial blockers (BB) are an alternative, especially for difficult airways. The EZ-bronchial blocker (EZB) is the newest device of the BB family.

\section{Methods:}

A randomised, controlled trial was conducted in 80 patients undergoing elective thoracic surgery using DLT or SLT plus EZB for lung separation (German Clinical Trial Register DRKS00014816). The objective of the study was to compare the clinical performance of EZB with DLT. Primary endpoint was total time to successful lung separation. Secondary endpoints were time subsections, quality of lung collapse, difficulty of intubation, any complications during the procedure, incidence of objective trauma of the oropharynx and supraglottic space and intubation-related subjective symptoms.

\section{Results:}

74 patients were included, DLT group $(n=38)$, EZB group $(n=36)$. Median total time for lung separation [IQR] in DLT group was 234 seconds [207 to 294] versus 298 seconds [243 to 369] in EZB group $(P=0.007)$. Quality of lung collapse was equal in both groups, DLT group $89.5 \%$ were excellent vs. $83.3 \%$ in the EZB group $(P=0.444)$. Inadequate lung collapse in five patients of the EZB group resulted in unsuccessful repositioning attempts and secondary DLT placement. Endoscopic examinations revealed significantly more carina trauma $(P=0.047)$ and subglottic haemorrhage $(P=0.047)$ in the DLT group. Additionally, postoperative subjective symptoms (sore throat, hoarseness) were more common in the DLT group, as were speech problems.

\section{Conclusions:}

Using the EZB results in prolonged lung separation compared to DLT, prima facie with equal quality of lung collapse for the thoracic surgeon. Five crossover cases demonstrated the superiority of the use of left-sided DLT especially in the indication for EZB for a right open thoracotomy or right video-assisted thoracoscopic surgery (VATS). Using the EZB showed only little evidence for reducing objective airway trauma e.g. less carina trauma as well as subjective complaints.

\section{Trial registration:}

German Clinical Trial Register DRKS00014816, prospectively registered on 07.06.2018

https://www.drks.de/drks_web/navigate.do?navigationld=trial.HTML\&TRIAL_ID=DRKS00014816

\section{Background}


There are many different airway devices on the market to establish lung separation for thoracic surgery (e.g. double-lumen intubation, bronchus blocker) (1). The worldwide most used procedure is the doublelumen tube (DLT) technique. DLT intubation has certain disadvantages, including an increased risk ofairway trauma (2-4), improper sizing and requirement for replacing it with a single-lumen tube (SLT) if postoperative ventilation is needed in the ICU. DLT intubation is more challenging compared to SLT intubation $(2,5,6)$. These disadvantages have resulted in the development of bronchus blockers (BB). BB such as the Univent torque control blocker, the wire-guided endobronchial Arndt Blocker and the Cohen Flex-tip Blocker represent alternatives to DLT intubation (7-9). In addition to these established BB devices, the EZ-Blocker ${ }^{\text {TM }}$ endobronchial blocker (EZB) (AnaesthetIQ BV, Rotterdam, The Netherlands), was introduced in 2010 in clinical practice (10). Contrary to the classic shape of 'single-ended' BBs, the 'double-ended'EZB has a Y-shaped distal end that mirrors the bifurcation of the trachea and has cuffs on both ends. Lung separation is achieved by inflating or deflating the bifurcated cuffs of the left or right side at the relevant main bronchus. The EZB presumably is easy to handle, with a low rate of malposition and fewer dislocations during repositioning and surgical manipulation. Safe and easy use of EZB has been described by researchers before $(11,12)$. Previous studies have shown that severe trauma and major complications like bronchial rupture were rare complications when using EZB (13).

To our knowledge, only a few trials have assessed the performance of EZB in comparison with DLT or other BB (14-17). Recent studies demonstrated longer times for placement of EZB in spite of shorter intubation times with SLT and equal efficiency for SLT plus EZB compared to DLT $(16,17)$. Presumably, this new EZB device needs longer process times for lung separation. In terms ofairway trauma and patient-centred outcome parameters, e.g. the incidence of hoarseness, the literature shows conflicting results $(16,17)$.

We investigated the impact of using SLT plus EZB instead of DLT for lung separation. We focused our investigation on the time needed for correct placement and successful lung separation. In contrast to other studies, in addition to questionnaires; we performed a flexible endoscopic investigation before and 24 hours after extubation for greater objectivity.

\section{Methods}

This study was approved by the University's Institutional Review Board (Ethikkommission Marburg, AZ17/18, 16.05.2018) and written informed consent was obtained from all subjects participating in the trial. The trial was registered prior to patient enrolment at the German Clinical Trials registry DRKS (DRKS00014816, Principal investigator: Dr. Joachim Risse, Date of registration: 07.06.2018). This randomised controlled and patient-blinded trial adhered to the CONSORT guidelines. This study was performed in compliance with recognised international standards, including the principles of the Declaration of Helsinki. This study uses established methodology from a previously published work of our Airway Research Group with the focus on thoracic anesthesia; therefore there are similarities and overlaps in the methodology (18). After providing written informed consent, adult patients scheduled for elective thoracic surgery requiring general anesthesia with the need for lung separation with American 
Society of Anaesthesiologists physical status I-IV were enrolled from 11.06.2018 until 14.02.2020. Exclusion criteria were patient age $<18$ years, non-elective surgery, pregnancy, scheduled rapid sequence induction (RSI), contraindication for DLT insertion or lung separation as well as abnormal physical status of the cervical spine.

\section{Primary endpoint}

Primary endpoint is the duration for correct placement of the different devices to separate the lungs for thoracic surgery (s). The total time measured for lung separation (s) consists of the following three time segments: preparation time (s), time to successful intubation (DLT or SLT) (s), time for placement of EZB and lung separation (time for bronchoscopic position check (s) plus the time required for correct placement (s)).

Preparation time (s) consisted of the measured time segments: time for device preparation (s) and time for bronchoscope preparation (s).

The time for successful intubation was defined as: blade passes mouth opening until positive capnography (visualisation of three expirations by capnography).

The time for bronchoscopic position check (s) was defined as: insertion of the bronchoscope until the current position is recognised. In the event of incorrect position of the device for lung separation, the additional time required for correction was measured. The time for correct placement (s) was defined as: start correction of current position until end of bronchoscopy and approval by the responsible performing anaesthesiologist. All time spans were measured and recorded by an independent investigator.

\section{Secondary endpoints}

In addition to total time for lung separation (primary endpoint) we analysed all the different time subsections as secondary endpoints. Further secondary endpoints of this study were quality of lung collapse, number of intubation attempts, assessment of difficulty, any complications and incidence of intubation-related injuries in both groups.

Quality of lung collapse was assessed by the surgeon (blinded to the randomisation result) under direct (thoracotomy) or indirect view (thoracoscopy). Classification of lung collapse was made on a three-pointLikert scale as previously described: 1 . excellent (complete collapse with perfect surgical exposure); 2 . moderate (total collapse, but still some air in the lungs); 3 . insufficient (no collapse or partial collapse with interference in surgical procedure) $(17,19)$.

Intubation-related injuries were investigated by two consecutive flexible endoscopic examinations (at the end of surgery and on postoperative day one (POD1)). We examined the oral cavity, the oropharynx, the supraglottic space, the vocal cords and the trachea. A follow-up survey by questionnaire according to an established protocol (18) was performed on POD1.

\section{Sample size calculation}


The sample size calculation was based on a previous study (17), which reported a mean placement time of $85 \pm 55$ seconds in the DLT group and $192 \pm 90$ seconds in the EZB group. Based on these results, an a priori power analysis was performed for the primary endpoint given a beta value of 0.80 and a significance level alpha of 0.05 . We calculated a minimum required sample size of 37 patients per group to detect a $15 \%$ difference in the time taken for placement of DLT or SLT plus EZB. Because of assumed drop-outs, we added a surcharge of three patients per group to achieve a study sample size of at least 80 patients. Power analysis was performed using G*Power3.1.9.6 for Mac OS X $(20,21)$.

\section{Randomisation and allocation concealment}

Allocation concealment was achieved using sealed opaque envelopes. Performance blinding was not possible due to study design. Patients and study investigators assessing postoperative outcome parameters were both unaware of the randomisation result. Statistical analysis was performed blinded to study allocation.

\section{Preoperative assessment}

Patients were pre-medicated with $3.75-7.5 \mathrm{mg}$ oral midazolam 45 minutes before surgery. In the induction area, patients were positioned supine, standard monitoring was applied according to current national guidelines and peripheral intravenous access was established. Patients received pre-oxygenation with $100 \%$ oxygen through a mask over five minutes. After pre-oxygenation, anesthesia was induced with $0.3 \mu \mathrm{g} \mathrm{kg}^{-1}$ sufentanil and $2 \mathrm{mg} \mathrm{kg}^{-1}$ propofol intravenously. Thereafter, $0.6 \mathrm{mg} \mathrm{kg}^{-1}$ rocuronium bromide was applied. Neuromuscular monitoring was performed by relaxometry train of four (TOF). Intubation was performed when full relaxation status (TOF 0/4) was reached. Maintenance of general anaesthesia was performed as total intravenous anaesthesia (TIVA) according to the local standards using propofol (4-6 $\left.\mathrm{mg} \mathrm{kg}^{-1} \mathrm{~h}^{-1}\right)$ and remifentanil $\left(15-25 \mu \mathrm{gg}^{-1} \mathrm{~h}^{-1}\right)$ adjusted according to the measured anaesthetic depth using bispectral index monitoring (BIS) at a target of 40-60.

The size of the DLT (RüschBronchopart; Teleflex Medical GmbH, Dublin, Ireland, 35-41 FR) used was determined for each patient according to Slinger et al. (22). Only left-sided DLTs were used in this trial. Intubation was performed using a conventional Maclntosh blade (size 3 or 4 ) as the first line in both groups. In case of difficulties, an intubation attempt with videolaryngoscopy (GVL) was allowed (GlideScope ${ }^{\circledR}$ size 3 or 4). All intubations were performed by the same four experienced anaesthesiologists with extensive training in all types of lung separation techniques including a training course explaining the standardised handling of EZB before starting the study. All bronchoscopies were performed with the Ambu ${ }^{\circledR}$ Broncho aScope 4 slim3.8/1.2 with the associated Ambu ${ }^{\circledR}$ aViewTM monitor (Fig. 1). A bronchoscopic check of the position of DLT or EZB and the time measurement were performed first directly after successful intubation. Correct placement of the respective device was rechecked again after patient positioning before starting the surgical procedure.

\section{Postoperative assessment}


The first endoscopic examination was performed at the end of surgery before extubation orally under general anaesthesia, while the follow-up endoscopic examination was performed transnasal on POD1 under topical anaesthesia. Stored endoscopic video clips were postprocessed for anonymisation and blinding. Thereafter, they were evaluated by three independent investigators (investigator-blinded). The hypopharynx, the vocal cords and the arytenoid cartilage were evaluated on the basis of various criteria. The different criteria were scored from according to the degree of injury $(0=$ not assessable, $1=$ without pathological findings, 2 = minor injuries, 3 = severe injuries). The results were averaged for further analysis. Second, the patients first completed a questionnaire (Validated H\&N35 Quality of Life Questionnaire Head and Neck Module and NRS) to express their subjective symptoms (hoarseness, etc.). NRS scores $1-3$ correspond to mild, scores $4-6$ to moderate and scores $\geq 7$ to severe symptoms. $H \& N$ Score ranged from 0-100. A high score correlated with a high degree of complaints and symptoms (23).

\section{Statistical analysis}

Statistical analysis was performed using SPSS (IBM Corp. Released 2016, IBM SPSS Statistics for Windows, Version 25.0, Armonk, NY: IBM Corp.). The normality of the distribution was assessed using the Shapiro-Wilk test. All values for descriptive statistics and outcome parameters were non-normally distributed. All non-normally distributed data are presented as median and interquartile range (IQR). Dichotomous outcome parameters are expressed as events (percentages). Non-parametric data were analysed using the Mann-Whitney U-test. $\mathrm{P}<0.05$ was considered statistically significant.

\section{Results}

For the study 123 patients were assessed for eligibility, in the period from 11.06.2018 until 14.02. 2020. Out of these patients 43 were excluded (Not met inclusion criteria $n=5$, declined to participate $n=16$, other reasons $n=22$ ). After the exclusion 80 patients were randomised for our study. Finally 74 completed the study and were included in the final analysis (Fig. 2). Two patients in the DLT group and four patients in the EZB group were excluded from the final analysis. Two participants randomised to the DLT group and two in the EZB group refused postoperative nasal endoscopic examination. In the EZB group, one participant needed rapid sequence induction and one participant needed long-term postoperative ventilation and was lost to follow-up. All six participants were excluded from the final analysis due to relevant study protocol violation, as predefined (Fig. 2). The groups showed no significant differences in demographics, preoperative airway assessments and descriptive intubation data (Table 1). 
Table 1

Biometric data and descriptive intubation data of patients enrolled in the study. Data are presented as median [IQR] or numbers (percentage)

\begin{tabular}{|c|c|c|}
\hline Parameter & $\begin{array}{l}\text { DLT } \\
(n=38)\end{array}$ & $\begin{array}{l}\text { EZB } \\
(n=36)\end{array}$ \\
\hline Gender (male/female) & $25 / 13$ & $23 / 13$ \\
\hline Age (years) & 64 [55 to 74] & 64 [59 to 72] \\
\hline Weight (kg) & 76 [63 to 90$]$ & $81[70$ to 101$]$ \\
\hline Height (cm) & 174 [168 to 178$]$ & 174 [165 to 181$]$ \\
\hline Body mass index $\left(\mathrm{kg} \mathrm{m}^{-2}\right)$ & 25.04 [21.34 to 28.72$]$ & 26.42 [24.34 to 30.81$]$ \\
\hline ASA n (\%): & $0(0 \%)$ & $1(3 \%)$ \\
\hline I & $9(24 \%)$ & $6(17 \%)$ \\
\hline II & $26(68 \%)$ & $27(75 \%)$ \\
\hline III & $3(8 \%)$ & $2(5 \%)$ \\
\hline \multicolumn{3}{|l|}{ IV } \\
\hline Mallampati score $\mathrm{n}(\%)$ : & $13(34 \%)$ & $14(39 \%)$ \\
\hline I & $20(53 \%)$ & $19(53 \%)$ \\
\hline II & $5(13 \%)$ & $3(8 \%)$ \\
\hline III & $0(0 \%)$ & $0(0 \%)$ \\
\hline \multicolumn{3}{|l|}{ IV } \\
\hline Cormack-Lehane score $n(\%)$ : & $22(58 \%)$ & $20(55 \%)$ \\
\hline $1^{\circ}$ & $13(34 \%)$ & $11(31 \%)$ \\
\hline $11^{\circ}$ & $3(8 \%)$ & $5(14 \%)$ \\
\hline $111^{\circ}$ & $0(0 \%)$ & $0(0 \%)$ \\
\hline \multicolumn{3}{|l|}{$\mathrm{IV}^{\circ}$} \\
\hline Patil-Test (cm): & $8.0[7$ to 9$]$ & 8.3 [7.5 to 9$]$ \\
\hline Mouth opening relaxed $(\mathrm{cm})$ : & 3.5 [3 to 4.5$]$ & $3.5[3.5$ to 4$]$ \\
\hline
\end{tabular}

\section{Primary endpoint}

Median total time for lung separation in the DLT group was significantly shorter in the EZB group compared to DLT group 234 seconds [207 to 294] versus 298 seconds [243 to 369] $(P=0.007)$ (Table 2 
and Fig. 3).

Page $8 / 25$ 
Table 2

Lung separation data: Time for intubation, preparation of the devices, bronchoscopic control. Data are presented as median [IQR] or numbers (percentage).

\begin{tabular}{|c|c|c|c|}
\hline Parameter & $\begin{array}{l}\text { DLT } \\
(n=38)\end{array}$ & $\begin{array}{l}\text { EZB } \\
(n=36)\end{array}$ & $\begin{array}{l}\text { Mann Whitney U-test } \\
\text { (P-Value) }\end{array}$ \\
\hline \multicolumn{4}{|l|}{ Primary endpoint (Total time) } \\
\hline $\begin{array}{l}\text { Total time for lung separation (s) } \\
\text { (preparation/intubation/separation) }\end{array}$ & $\begin{array}{l}234[207 \\
\text { to } 294]\end{array}$ & $\begin{array}{l}298[243 \\
\text { to } 369]\end{array}$ & $0.007^{*}$ \\
\hline \multicolumn{4}{|l|}{ Secondary endpoints (Time subsections) } \\
\hline $\begin{array}{l}\text { Preparation time (s) } \\
\text { (device + bronchoscope) }\end{array}$ & $\begin{array}{l}76[64 \text { to } \\
111]\end{array}$ & $\begin{array}{l}119[95 \text { to } \\
149]\end{array}$ & $<0.001^{\star}$ \\
\hline Time for successful intubation (s) & $\begin{array}{l}69[55 \text { to } \\
97]\end{array}$ & $\begin{array}{l}47[35 \text { to } \\
65]\end{array}$ & $<0.001^{*}$ \\
\hline Time for bronchoscopic position check (s) & $\begin{array}{l}50[29 \text { to } \\
94]\end{array}$ & $\begin{array}{l}85[45 \text { to } \\
113]\end{array}$ & 0,107 \\
\hline Time for correct placement (s) & $5[0$ to 38$]$ & $\begin{array}{l}22[0 \text { to } \\
68]\end{array}$ & 0,051 \\
\hline Time for bronchoscope preparation (s) & $\begin{array}{l}28[19 \text { to } \\
35]\end{array}$ & $\begin{array}{l}23[20 \text { to } \\
32]\end{array}$ & 0.349 \\
\hline Time for device preparation (s) & $\begin{array}{l}49[41 \text { to } \\
70]\end{array}$ & $\begin{array}{l}97[74 \text { to } \\
117]\end{array}$ & $<0.001^{*}$ \\
\hline $\begin{array}{l}\text { Time for lung separation without preparation } \\
\text { time (s) }\end{array}$ & $\begin{array}{l}140[112 \\
\text { to } 222]\end{array}$ & $\begin{array}{l}165[125 \\
\text { to } 203]\end{array}$ & 0.479 \\
\hline Correct device position after & $27(71 \%)$ & $16(44 \%)$ & $0.021^{*}$ \\
\hline intubation $\mathrm{n}(\%)$ : & $11(29 \%)$ & $20(56 \%)$ & \\
\hline \multicolumn{4}{|l|}{ yes } \\
\hline \multicolumn{4}{|l|}{ no } \\
\hline Method of intubation $\mathrm{n}(\%)$ : & $29(87 \%)$ & $28(86 \%)$ & 0.927 \\
\hline DL & $9(13 \%)$ & $8(14 \%)$ & \\
\hline \multicolumn{4}{|l|}{ GVL } \\
\hline Change method of intubation $n(\%)$ : & $3(8 \%)$ & $2(6 \%)$ & 0.691 \\
\hline yes & $35(92 \%)$ & $34(94 \%)$ & \\
\hline no & & & \\
\hline
\end{tabular}




\begin{tabular}{|llll|}
\hline Parameter & $\begin{array}{l}\text { DLT } \\
(\mathbf{n = 3 8})\end{array}$ & $\begin{array}{l}\text { EZB } \\
(\mathbf{n = 3 6 )}\end{array}$ & $\begin{array}{l}\text { Mann Whitney U-test } \\
\text { (P-Value) }\end{array}$ \\
\hline First attempt success $\mathrm{n}(\%):$ & $29(76 \%)$ & $32(89 \%)$ & 0.158 \\
yes & $9(24 \%)$ & $4(11 \%)$ & \\
no & & & \\
\hline Intubation attempts $\mathrm{n}(\%):$ & $27(71 \%)$ & $29(81 \%)$ & 0.32 \\
1 & $10(26 \%)$ & $7(19 \%)$ & \\
2 & $0(0 \%)$ & $0(0 \%)$ & \\
3 & $1(3 \%)$ & $0(0 \%)$ & \\
$>3$ & & & \\
\hline *Statistically significant & & & \\
\hline Seconday endpoints & & & \\
\hline
\end{tabular}

Regarding the secondary endpoints, the preparation time was significantly longer in the EZB group with 119 seconds [95 to 149] compared to the DLT group 76 seconds [64 to 111] $(P=0.001)$. The time to successful intubation in the EZB group was significantly shorter with 47 seconds [35 to 65] versus 69 seconds [55 to 97] in the DLT group $(P=0.001)$. The times for correct lung separation after intubation did not differ between the two groups (Table 2).

First-attempt success did not differ significantly between the DLT group (76\%) and the EZB group (89\%) $(P>0.05)$ (Table 2). There was no statistically significant difference between groups regarding the frequency of intubation attempts $(P>0.05)$.

During bronchoscopic control, correct positioning of the DLT or SLT plus EZB for selective lung ventilation was reported in $71 \%$ in the DLT group directly after successful endobronchial intubation, whereas only $44 \%$ of the devices in the EZB group were adequately positioned $(P=0.021)($ Table 2$)$.

The quality of lung collapse was equal in both groups (DLT group $89.5 \%$ were excellent vs. $83.3 \%$ EZB Group $(P=0.444)$ ) (Fig. 4). Inadequate lung collapse in five patients of the EZB group resulted in unsuccessful repositioning attempts and secondary DLT placement. These five crossover cases showed adequate lung separation after DLT placement.

There were significantly more carina traumas in the DLT group $(P=0.047)($ Table 3$)$. There was no other significant difference in terms of direct complications after intubation between the two groups. 
Table 3

Assessment of difficulty and complications. Data are presented as number (percentage).

\begin{tabular}{|c|c|c|c|}
\hline Parameter & $\begin{array}{l}\text { DLT } \\
(n=38)\end{array}$ & $\begin{array}{l}\text { EZB } \\
(n=36)\end{array}$ & Mann Whitney U-test (P-value) \\
\hline $\begin{array}{l}\mathrm{SpO}_{2}<85 \% \mathrm{n}(\%): \\
\text { yes } \\
\text { no }\end{array}$ & $\begin{array}{l}1(3 \%) \\
37(97 \%)\end{array}$ & $\begin{array}{l}0(0 \%) \\
36(100 \%)\end{array}$ & 0.33 \\
\hline $\begin{array}{l}\text { Bronchospasm n (\%): } \\
\text { yes } \\
\text { no }\end{array}$ & $\begin{array}{l}1(3 \%) \\
37(97 \%)\end{array}$ & $\begin{array}{l}0(0 \%) \\
36(100 \%)\end{array}$ & 0.33 \\
\hline $\begin{array}{l}\text { Cardiac arrhythmia n (\%): } \\
\text { yes } \\
\text { no }\end{array}$ & $\begin{array}{l}1(3 \%) \\
37(97 \%)\end{array}$ & $\begin{array}{l}0(0 \%) \\
36(100 \%)\end{array}$ & 0.33 \\
\hline $\begin{array}{l}\text { Blood on devicen }(\%) \text { : } \\
\text { yes } \\
\text { no }\end{array}$ & $\begin{array}{l}3(8 \%) \\
35(92 \%)\end{array}$ & $\begin{array}{l}0(0 \%) \\
36(100 \%)\end{array}$ & 0.087 \\
\hline $\begin{array}{l}\text { Carina trauma } n(\%) \text { : } \\
\text { yes } \\
\text { no }\end{array}$ & $\begin{array}{l}4(11 \%) \\
34(89 \%)\end{array}$ & $\begin{array}{l}0(0 \%) \\
36(100 \%)\end{array}$ & $0.047 *$ \\
\hline
\end{tabular}

When analysing the postoperative questionnaires (H\&N35 and NRS scores) to record the subjective symptoms after intubation, significant more incidence of sore throat, hoarseness and speech problems were found in the DLT group. With the NRS score, the items sore throat $(P=0.009)$ and hoarseness $(P=$ 0.02) were significantly lower in the EZB group (Table 4). With the H\&N35 score the two items sore throat $(P=0.015)$ and speech problems $(P=0.047)$ were significantly lower in the EZB group (Table 5). However, there was no difference in the valid total H\&N35 score between the two groups $(P=0.064)$. 
Table 4

Results of parameters additionally examined with numerical rating scale (NRS). NRS scores 1-3 correspond to mild, scores 4-6 to moderate and scores $\geq 7$ to severe symptoms. Values are expressed as the number of patients or as the total number in percent.

\begin{tabular}{|llll|}
\hline Parameter of the NRS score & $\begin{array}{l}\text { DLT } \\
(\mathbf{n = 3 8})\end{array}$ & $\begin{array}{l}\text { EZB } \\
(\mathbf{n}=\mathbf{3 6})\end{array}$ & $\begin{array}{l}\text { U-test } \\
\text { (P-value) }\end{array}$ \\
\hline Sore throat n (mild/moderate/severe) (total in \%) & $9 / 0 / 0(23.7 \%)$ & $1 / 0 / 0$ & $0.009 *$ \\
& & $(2.8 \%)$ & \\
\hline Dysphagia n (mild/moderate/severe) (total in \%) & $6 / 1 / 0(18.4 \%)$ & $1 / 2 / 0$ & 0.247 \\
& & $(8.3 \%)$ & \\
\hline Cough n (mild/moderate/severe) (total in \%) & $11 / 9 / 0(52.6 \%)$ & $17 / 5 / 0(61.1 \%)$ & 0.916 \\
\hline Hoarseness n (mild/moderate/severe) (total in \%) & $6 / 9 / 3(47.4 \%)$ & $9 / 1 / 0$ & $0.02 *$ \\
\hline *Statistically significant & & $(27.8 \%)$ & \\
\hline
\end{tabular}

Table 5

Results of relevant selected parameters from evaluation of the H\&N35 Quality of Life Questionnaire Head and Neck Module (H\&N Score). Data are presented as median [IQR].

\begin{tabular}{|llll|}
\hline Parameter (H\&N Score) & $\begin{array}{l}\text { DLT } \\
(\mathbf{n}=\mathbf{3 8})\end{array}$ & $\begin{array}{l}\text { EZB } \\
(\mathbf{n}=36)\end{array}$ & Mann Whitney U-test (P-value) \\
\hline Sore throat & $0[0$ to 33$]$ & $0[0$ to 0$]$ & $0.015^{\star}$ \\
\hline Dysphagia & $0[0$ to 0$]$ & $0[0$ to 0$]$ & 0.202 \\
\hline Cough & $33[0$ to 33$]$ & $33[0$ to 67$]$ & 0.411 \\
\hline Hoarseness & $0[0$ to 67$]$ & $0[0$ to 33$]$ & 0.077 \\
\hline Dry mouth & $67[0$ to 67$]$ & $33[0$ to 67$]$ & 0.429 \\
\hline Viscous mucus & $33[0$ to 33$]$ & $0[0$ to 33$]$ & 0.131 \\
\hline Paraesthesia & $0[0$ to 0$]$ & $0[0$ to 0$]$ & 0.143 \\
\hline Speech problems & $0[0$ to 33$]$ & $0[0$ to 0$]$ & 0.047 \\
\hline Mouth opening problems & $0[0$ to 0$]$ & $0[0$ to 0$]$ & 0.071 \\
\hline Toothache & $0[0$ to 0$]$ & $0[0$ to 0$]$ & 0.613 \\
\hline Total H\&N35 score & $17[7$ to 23$]$ & $12[7$ to 17$]$ & 0.064 \\
\hline *Statistically significant & & & \\
\hline
\end{tabular}


In contrast to the subjective symptoms, postoperative endoscopic examinations revealed significant differences in the EZB group compared to the DLT group in terms of objective trauma, i.e. subglottic haemorrhage $(P=0.047)$ (Table 6). 
Table 6

Data of reported intubation related injuries from two transnasal endoscopic examinations; before and 24 h after extubation. All different criteria were scored from 0 to 3 . $(0=$ not assessable, $1=$ without pathological findings, 2 = minor injuries, $3=$ severe injuries). Values are expressed as median (5th -25 th -75th -95th percentile).

\begin{tabular}{|c|c|c|c|c|c|c|}
\hline Parameter & $\begin{array}{l}\text { DLT } \\
\text { pre- } \\
\text { extubation }\end{array}$ & $\begin{array}{l}\text { EZB } \\
\text { pre- } \\
\text { extubation }\end{array}$ & $\begin{array}{l}\text { U-test } \\
(\mathrm{P}- \\
\text { value })\end{array}$ & $\begin{array}{l}\text { DLT } \\
\text { 24h post- } \\
\text { extubation }\end{array}$ & $\begin{array}{l}\text { EZB } \\
\text { 24h post- } \\
\text { extubation }\end{array}$ & $\begin{array}{l}\text { U-test } \\
(\mathrm{P} \text { - } \\
\text { value) }\end{array}$ \\
\hline $\begin{array}{l}\text { Vocal cord } \\
\text { swelling }\end{array}$ & $\begin{array}{l}1.00(1.00- \\
1.00-1.00- \\
1.67)\end{array}$ & $\begin{array}{l}1.00(1.00- \\
1.00-1.00- \\
2.00)\end{array}$ & 0.457 & $\begin{array}{l}1.00(1.00- \\
1.00-1.33- \\
1.67)\end{array}$ & $\begin{array}{l}1.00(1.00- \\
1.00-1.33- \\
1.67)\end{array}$ & 0.711 \\
\hline $\begin{array}{l}\text { Vocal cord } \\
\text { redness }\end{array}$ & $\begin{array}{l}1.00(1.00- \\
1.00-1.00- \\
1.33)\end{array}$ & $\begin{array}{l}1.00(1.00- \\
1.00-1.00- \\
1.33)\end{array}$ & 0.659 & $\begin{array}{l}1.00(1.00- \\
1.00-1.00- \\
1.33)\end{array}$ & $\begin{array}{l}1.00(1.00- \\
1.00-1.00- \\
1.50)\end{array}$ & 0.369 \\
\hline $\begin{array}{l}\text { Vocal cord } \\
\text { oedema }\end{array}$ & $\begin{array}{l}1.00(1.00- \\
1.00-1.00- \\
1.33)\end{array}$ & $\begin{array}{l}1.00(1.00- \\
1.00-1.00- \\
1.67)\end{array}$ & 0.111 & $\begin{array}{l}1.00(1.00- \\
1.00-1.00- \\
1.33)\end{array}$ & $\begin{array}{l}1.00(1.00- \\
1.00-1.00- \\
1.50)\end{array}$ & 0.974 \\
\hline $\begin{array}{l}\text { Vocal cord } \\
\text { erythema }\end{array}$ & $\begin{array}{l}1.00(1.00- \\
1.00-1.00- \\
1.00)\end{array}$ & $\begin{array}{l}1.00(1.00- \\
1.00-1.00- \\
1.00)\end{array}$ & 1.0 & $\begin{array}{l}1.00(1.00- \\
1.00-1.00- \\
1.33)\end{array}$ & $\begin{array}{l}1.00(1.00- \\
1.00-1.00- \\
1.50)\end{array}$ & 0.795 \\
\hline $\begin{array}{l}\text { Vocal cord } \\
\text { hematoma }\end{array}$ & $\begin{array}{l}1.00(1.00- \\
1.00-1.00- \\
1.00)\end{array}$ & $\begin{array}{l}1.00(1.00- \\
1.00-1.00- \\
1.33)\end{array}$ & 0.539 & $\begin{array}{l}1.00(1.00- \\
1.00-1.00- \\
1.67)\end{array}$ & $\begin{array}{l}1.00(1.00- \\
1.00-1.00- \\
1.67)\end{array}$ & 0.543 \\
\hline $\begin{array}{l}\text { Vocal cord } \\
\text { haemorrhage }\end{array}$ & $\begin{array}{l}1.00(1.00- \\
1.00-1.00- \\
1.00)\end{array}$ & $\begin{array}{l}1.00(1.00- \\
1.00-1.00- \\
1.00)\end{array}$ & 0.325 & $\begin{array}{l}1.00(1.00- \\
1.00-1.00- \\
1.33)\end{array}$ & $\begin{array}{l}1.00(1.00- \\
1.00-1.00- \\
1.33)\end{array}$ & 0.207 \\
\hline $\begin{array}{l}\text { Vocal cord } \\
\text { granuloma }\end{array}$ & $\begin{array}{l}1.00(1.00- \\
1.00-1.00- \\
1.00)\end{array}$ & $\begin{array}{l}1.00(1.00- \\
1.00-1.00- \\
1.00)\end{array}$ & 0.325 & $\begin{array}{l}1.00(1.00- \\
1.00-1.00- \\
1.33)\end{array}$ & $\begin{array}{l}1.00(1.00- \\
1.00-1.00- \\
1.00)\end{array}$ & 0.179 \\
\hline $\begin{array}{l}\text { Vocal cord } \\
\text { mobility }\end{array}$ & - & - & - & $\begin{array}{l}1.00(1.00- \\
1.00-1.00- \\
1.33)\end{array}$ & $\begin{array}{l}1.00(1.00- \\
1.00-1.00- \\
1.33)\end{array}$ & 0.874 \\
\hline $\begin{array}{l}\text { Arytenoid } \\
\text { cartilage } \\
\text { trauma }\end{array}$ & $\begin{array}{l}1.00(1.00- \\
1.00-1.00- \\
1.00)\end{array}$ & $\begin{array}{l}1.00(1.00- \\
1.00-1.00- \\
1.00)\end{array}$ & 0.332 & $\begin{array}{l}1.00(1.00- \\
1.00-1.00- \\
1.33)\end{array}$ & $\begin{array}{l}1.00(1.00- \\
1.00-1.00- \\
1.33)\end{array}$ & 0.564 \\
\hline $\begin{array}{l}\text { Hypopharynx } \\
\text { redness }\end{array}$ & $\begin{array}{l}1.33(1.00- \\
1.00-1.50- \\
2.00)\end{array}$ & $\begin{array}{l}1.33(1.00- \\
1.00-1.33- \\
1.67)\end{array}$ & 0.995 & $\begin{array}{l}1.00(1.00- \\
1.00-1.33- \\
1.33)\end{array}$ & $\begin{array}{l}1.00(1.00- \\
1.00-1.33- \\
1.67)\end{array}$ & 0.930 \\
\hline $\begin{array}{l}\text { Hypopharynx } \\
\text { oedema }\end{array}$ & $\begin{array}{l}1.00(1.00- \\
1.00-1.00- \\
1.67)\end{array}$ & $\begin{array}{l}1.00(1.00- \\
1.00-1.33- \\
1.67)\end{array}$ & 0.065 & $\begin{array}{l}1.00(1.00- \\
1.00-1.00- \\
1.33)\end{array}$ & $\begin{array}{l}1.00(1.00- \\
1.00-1.00- \\
1.33)\end{array}$ & 0.364 \\
\hline
\end{tabular}




\begin{tabular}{|c|c|c|c|c|c|c|}
\hline \multirow[t]{2}{*}{ Parameter } & DLT & EZB & U-test & DLT & EZB & U-test \\
\hline & $\begin{array}{l}\text { pre- } \\
\text { extubation }\end{array}$ & $\begin{array}{l}\text { pre- } \\
\text { extubation }\end{array}$ & $\begin{array}{l}\text { (P- } \\
\text { value) }\end{array}$ & $\begin{array}{l}24 \mathrm{~h} \text { post- } \\
\text { extubation }\end{array}$ & $\begin{array}{l}24 \mathrm{~h} \text { post- } \\
\text { extubation }\end{array}$ & $\begin{array}{l}\text { (P- } \\
\text { value) }\end{array}$ \\
\hline $\begin{array}{l}\text { Hypopharynx } \\
\text { hematoma }\end{array}$ & $\begin{array}{l}1.00(1.00- \\
1.00-1.00- \\
1.33)\end{array}$ & $\begin{array}{l}1.00(1.00- \\
1.00-1.00- \\
1.50)\end{array}$ & 0.522 & $\begin{array}{l}1.00(1.00- \\
1.00-1.00- \\
1.33)\end{array}$ & $\begin{array}{l}1.00(1.00- \\
1.00-1.00- \\
1.33)\end{array}$ & 0.910 \\
\hline $\begin{array}{l}\text { Hypopharynx } \\
\text { haemorrhage }\end{array}$ & $\begin{array}{l}1.00(1.00- \\
1.00-1.33- \\
2.00)\end{array}$ & $\begin{array}{l}1.00(1.00- \\
1.00-1.33- \\
2.00)\end{array}$ & 0.298 & $\begin{array}{l}1.00(1.00- \\
1.00-1.00- \\
1.33)\end{array}$ & $\begin{array}{l}1.00(1.00- \\
1.00-1.00- \\
1.33)\end{array}$ & 0.564 \\
\hline $\begin{array}{l}\text { Subglottic } \\
\text { redness }\end{array}$ & - & - & - & $\begin{array}{l}1.00(1.00- \\
1.00-1.00- \\
1.67)\end{array}$ & $\begin{array}{l}1.00(1.00- \\
1.00-1.00- \\
1.00)\end{array}$ & 0.266 \\
\hline $\begin{array}{l}\text { Subglottic } \\
\text { oedema }\end{array}$ & - & - & - & $\begin{array}{l}1.00(1.00- \\
1.00-1.00- \\
1.00)\end{array}$ & $\begin{array}{l}1.00(1.00- \\
1.00-1.00- \\
1.00)\end{array}$ & 0.332 \\
\hline $\begin{array}{l}\text { Subglottic } \\
\text { hematoma }\end{array}$ & - & - & - & $\begin{array}{l}1.00(1.00- \\
1.00-1.00- \\
1.50)\end{array}$ & $\begin{array}{l}1.00(1.00- \\
1.00-1.00- \\
1.00)\end{array}$ & 0.061 \\
\hline $\begin{array}{l}\text { Subglottic } \\
\text { haemorrhage }\end{array}$ & - & - & - & $\begin{array}{l}1.00(1.00- \\
1.00-1.33- \\
1.67)\end{array}$ & $\begin{array}{l}1.00(1.00- \\
1.00-1.00- \\
1.00)\end{array}$ & 0.047 \\
\hline
\end{tabular}

\section{Discussion}

Our study showed a significantly prolonged time required for successful lung separation using EZB. In addition, there was a significantly higher incidence of malpositioned devices in the EZB group, but on the other hand we found a significantly higher rate of airway trauma as well as subjective complaints in the DLT group.

\section{Process times}

Prolonged intubation times for EZB were shown in previous studies and have a greater risk of hypoxia $(16,17)$. However, the combination of EZB with SLT guarantees a secured airway and oxygenation while the EZB is positioned.

The prolonged total time for successful lung separation was notably influenced by the prolonged preparation time. A shorter intubation time for SLT seems to be relativised based on the total time for a successful lung separation. This seems logical, because SLT plus EZB is a two-step procedure. A shorter intubation time is certainly relevant in patients with a higher risk of aspiration and desaturation. 
In our opinion, the marginal difference in the process times is in the end not clinically relevant. In the case of emergency intubation due to pulmonary bleeding, rapid intubation with SLT plus EZB may offer advantages, because DLT intubation requires more expertise. Therefore, when using EZB, there should also be a focus on non-elective use in the intensive care units and emergency rooms.

\section{Incidence of device malposition}

Previous studies of Ruetzler et al. showed a lower incidence of malpositions with DLT (10\%) for blind insertion without flexible fibre optic bronchoscopy (FOB) compared to EZB (79\%) (17). In contrast, Mourisse and colleagues showed a very high incidence of initial malpositions and need for repositioning the device during FOB in both groups (85\% DLT vs. $74 \%$ EZB) (16). With $29 \%$ initial malpositions, we had

a significantly lower incidence for DLT, similar to the results by Ruetzler et al. With EZB the position during FOB had to be corrected in more than half of the cases (56\%). Initial malpositions are caused by too-deep positioning of the SLT used for introducing the EZB (11). This was the most common cause for malposition in our study cohort as well. Because of the high incidence of malposition we underline the recommendation to use FOB for the placement of EZB (16). A correspondingly thin bronchoscope and an endotracheal tube as large as possible are obligate in order to fit parallel with EZB.

\section{Success and quality of lung collapse}

Overall, we had good results for both techniques based on successful OLV. In all intubations with SLT, we did not have a single case of entrapment of an EZB in the Murphy eye (24).

OLV with EZB was described before as a safe and easy technique with good quality of lung collapse (11, 12). We were able to confirm these findings with our data. The only two randomised trials between DLT and EZB so far have shown no difference in quality of lung collapse assessed by the surgeon $(16,17)$.

Prima facie, our study results seem to confirm the previous ones. However, there was only a change in method to a left-sided DLT in five of six cases in the EZB group, if the quality of collapse was not excellent. Conversely, in the DLT group with repositioning of the left-sided DLT, sufficient surgery conditions intraoperatively could be achieved in all cases. In all five cases, the reason was the inadequate closing of the aperture of the right upper lobe bronchus. Adequate OLV by EZB seems to cause difficulties, especially for right-sided thoracotomies $(12,25)$. The shorter distance between the main carina and the aperture of the right upper lobe can make the use of EZB difficult. Therefore, we recommend reconsidering the indication for EZB for a right open thoracotomy or video-assisted thoracoscopic surgery (VATS).

\section{Incidence of airway trauma}

With equal quality of lung collapse and less traumatic damage of the glottis and subglottic level, the extended time to separate the lungs with EZB takes a back seat. In our study, more carina trauma and subglottic haemorrhage in the endoscopic follow-up were the objective evidence for airway trauma. Severe trauma such as bronchus perforation did not occur in our patients (13) and no patients required intervention to treat an airway damage. 
Our findings are in agreement with the findings of Mourisse et al., who described placing EZB took more time and had a lower rate of airway injury (16). In contrast we found significantly more carina trauma by first endoscopic follow-up in the DLT group. We expected more carina trauma with EZB, because of the initial blind insertion and the $y$-shaped distal end sticking fixed on the carina. We conclude that pressure and forces during blind introduction and rotation manoeuvre of the left-sided DLT in the tracheal part might cause more airway trauma.

Regarding subjective symptoms, there are controversial results in the literature by Mourisse et al. and Ruetzler et al. $(16,17)$. Our results show a significant trend to increased subjective complaints after DLT. We could show for individual items of H\&N35 score and items of NRS score significantly more subjective symptoms 24 hours after extubation in the DLT group. But the recognised total score of H\&N35 questionnaire showed no significant difference. The question remains as to whether the questionnaires used are sensitive enough to record differences in subjective symptoms.

We suggest from our results to waive blind insertion of EZB and to perform insertion under FOB control. This might shorten the procedure and prevent even more airway trauma of the carina.

\section{Limitations}

Although time to intubation or time to lung separation is commonly used in airway studies, because they are methodologically easy to compare, the clinical relevance remains questionable. Operators were not blinded to the intubation device used. Nevertheless, the patient and follow-up endoscopic examinations were anonymised and blinded. Further limitation might be that the operators were not equally experienced with both devices. A small number of patients with an expected difficult airway (Mallampati 3 and 4 ) and the low incidence of predicted difficult airways (CL 3 and 4 ) is a further limitation of our study. EZB is an important technique for OLV in patients with an expected difficult airway. Furthermore, we cannot exclude injuries by the endoscopic flexible bronchoscopies at the follow-up itself, although they were all done by experienced investigators. Lastly, we did not investigate a long-term outcome with our follow-up at 24 hours after surgery.

\section{Conclusions}

In summary, our randomised controlled trial showed that the total time for selective lung ventilation with SLT plus EZB is longer compared to DLT and the quality of lung collapse for the thoracic surgeon is prima facie equivalent. Five crossover cases in the EZB group resulted in unsuccessful repositioning attempts and secondary DLT placement to achieve adequate lung separation. In all five cases the reason was inadequate closing of the aperture of the right upper lobe bronchus. Therefore, we recommend reconsidering the indication for EZB for a right open thoracotomy or right video-assisted thoracoscopic surgery (VATS). Despite some advantages due to less objective airway injuries, there was no subjective difference for the patient as a relevant patient-centred outcome parameter. Further studies are needed to underline the advantages of EZB for lung separation in thoracic surgery. 


\section{List Of Abbreviations}

BB Bronchial blocker

BIS Bispectral index monitoring

CL Cormack and Lehane

DL Direct laryngoscopy

DLT Double lumen tube

EZB EZ-bronchial blocker

FOB Flexible fibreoptic bronchoscopy

GVL GlideScope videolaryngoscopy

ICU Intensive care unit

IQR interquartile range

NRS Numeric rating scale

OR Operating room

OLV One-lung-ventilation

POD1 Postoperative day one

RSI Rapid sequence induction

SLT Single lumen tube

SOP Standard operating procedure

TIVA Total intravenous anaesthesia

TOF Train of four

VATS Video-assisted thoracoscopic surgery

\section{Declarations}

\section{Ethics approval and consent to participate}


Ethics approval was granted by the Ethics Committee of Philipps-University Marburg, Baldingerstrasse/ Postfach 2360, 35032 Marburg, Germany AZ 17/18; 16.05.2018. This study was performed in compliance with recognised international standards, including the principles of the Declaration of Helsinki. All experiments and data collection were performed with prior informed consent to participate. Written consent to participate in the study was obtained from each participant.

\section{Consent for publication}

Not applicable.

\section{Availability of data and material}

The data that support the findings of this study are available from the corresponding author. The datasets used and analysed during the current study are available from the corresponding author on reasonable request.

\section{Competing interests}

The authors declare that they have no competing interests.

\section{Funding}

No funding was provided.

\section{Authors' individual contributions}

JR, KS, AKS, KMM analysed and interpreted the patient data. JR, KMM, AKS, HCD and TW wrote the manuscript. KS, $\mathrm{CF}$, and $\mathrm{KMM}$ helped acquire the data and revised the manuscript. HW helped revise and edit the manuscript. CF and HW provided the conceptual design and revised the manuscript. All authors read and approved the final manuscript.

\section{Acknowledgments}

Not applicable

\section{Authors' information}

Our study adheres to CONSORT guidelines and we included in the section supporting information a completed CONSORT checklist and CONSORT diagram

\section{References}

1. Meggiolaro KM, Wulf H, Feldmann C, Wiesmann T, Schubert AK, Risse J. [Airway management for lung separation in thoracic surgery: An update]. Anaesthesist. 2018;67(8):555-67. 
2. Liu H, Jahr JS, Sullivan E, Waters PF. Tracheobronchial rupture after double-lumen endotracheal intubation. J Cardiothorac Vasc Anesth. 2004;18(2):228-33.

3. Yüceyar L, Kaynak K, Cantürk E, Aykaç B. Bronchial rupture with a left-sided polyvinylchloride doublelumen tube. Acta Anaesthesiol Scand. 2003;47(5):622-5.

4. Knoll H, Ziegeler S, Schreiber JU, Buchinger H, Bialas P, Semyonov K, et al. Airway injuries after onelung ventilation: a comparison between double-lumen tube and endobronchial blocker: a randomized, prospective, controlled trial. Anesthesiology. 2006;105(3):471-7.

5. Defosse J, Schieren M, Böhmer A, von Dossow V, Loop T, Wappler F, et al. [A Germany-wide survey on anaesthesia in thoracic surgery]. Anaesthesist. 2016;65(6):449-57.

6. Zhong T, Wang W, Chen J, Ran L, Story DA. Sore throat or hoarse voice with bronchial blockers or double-lumen tubes for lung isolation: a randomised, prospective trial. Anaesth Intensive Care. 2009;37(3):441-6.

7. Cohen $\mathrm{E}$. The Cohen flexitip endobronchial blocker: an alternative to a double lumen tube. Anesth Analg. 2005;101(6):1877-9.

8. Arndt GA, DeLessio ST, Kranner PW, Orzepowski W, Ceranski B, Valtysson B. One-lung ventilation when intubation is difficult-presentation of a new endobronchial blocker. Acta Anaesthesiol Scand. 1999;43(3):356-8.

9. Neustein SM. The use of bronchial blockers for providing one-lung ventilation. J Cardiothorac Vasc Anesth. 2009;23(6):860-8.

10. Mungroop HE, Wai PT, Morei MN, Loef BG, Epema AH. Lung isolation with a new Y-shaped endobronchial blocking device, the EZ-Blocker. Br J Anaesth. 2010;104(1):119-20.

11. Végh T, Juhász M, Enyedi A, Takács I, Kollár J, Fülesdi B. Clinical experience with a new endobrochial blocker: the EZ-blocker. J Anesth. 2012;26(3):375-80.

12. Moritz A, Irouschek A, Birkholz T, Prottengeier J, Sirbu H, Schmidt J. The EZ-blocker for one-lung ventilation in patients undergoing thoracic surgery: clinical applications and experience in 100 cases in a routine clinical setting. J Cardiothorac Surg. 2018;13(1):77.

13. van de Pas JM, van der Woude MC, Belgers HJ, Hulsewé KW, de Loos ER. Bronchus perforation by EZ-BlockerTM endobronchial blocker during esophageal resection after neoadjuvant chemoradiation -a case report. Korean J Anesthesiol. 2019;72(2):184-7.

14. Hoşten T, Aksu C, Kuş A, Cesur S, Türkyılmaz N, Solak M. Comparison of Univent tube and EZ blocker in one lung ventilation; airway pressures and gas exchange. J Clin Monit Comput. 2018;32(2):32733.

15. Kus A, Hosten T, Gurkan Y, Gul Akgul A, Solak M, Toker K. A comparison of the EZ-Blocker with a Cohen Flex-Tip blocker for one-lung ventilation. J Cardiothorac Vasc Anesth. 2014;28(4):896-9.

16. Mourisse J, Liesveld J, Verhagen A, van Rooij G, van der Heide S, Schuurbiers-Siebers O, et al. Efficiency, efficacy, and safety of EZ-blocker compared with left-sided double-lumen tube for one-lung ventilation. Anesthesiology. 2013;118(3):550-61. 
17. Ruetzler K, Grubhofer G, Schmid W, Papp D, Nabecker S, Hutschala D, et al. Randomized clinical trial comparing double-lumen tube and EZ-Blocker for single-lung ventilation. $\mathrm{Br} \mathrm{J}$ Anaesth. 2011;106(6):896-902.

18. Risse J, Schubert AK, Wiesmann T, Huelshoff A, Stay D, Zentgraf M, et al. Videolaryngoscopy versus direct laryngoscopy for double-lumen endotracheal tube intubation in thoracic surgery - a randomised controlled clinical trial. BMC Anesthesiol. 2020;20(1):150.

19. Campos JH, Kernstine KH. A comparison of a left-sided Broncho-Cath with the torque control blocker univent and the wire-guided blocker. Anesth Analg. 2003;96(1):283-9, table of contents.

20. Faul F, Erdfelder E, Buchner A, Lang AG. Statistical power analyses using G*Power 3.1: tests for correlation and regression analyses. Behav Res Methods. 2009;41(4):1149-60.

21. Faul F, Erdfelder E, Lang AG, Buchner A. G*Power 3: a flexible statistical power analysis program for the social, behavioral, and biomedical sciences. Behav Res Methods. 2007;39(2):175-91.

22. Slinger P. A view of and through double-lumen tubes. J Cardiothorac Vasc Anesth. 2003;17(3):287-8.

23. Fayers P, Aaronson N, Bjordal K, Sullivan M. The EORTC QLQ-C30 Scoring Manual. 3rd ed2001. 1-33 p.

24. Tang J, Merritt RE, Essandoh M. Entrapment of an EZ-Blocker in the Murphy Eye of an Endotracheal Tube. J Cardiothorac Vasc Anesth. 2019;33(10):2873-4.

25. Templeton TW, Templeton LB, Lawrence AE, Sieren LM, Downard MG, Ririe DG. An initial experience with an Extraluminal EZ-Blocker. Paediatr Anaesth. 2018;28(4):347-51.

\section{Figures}




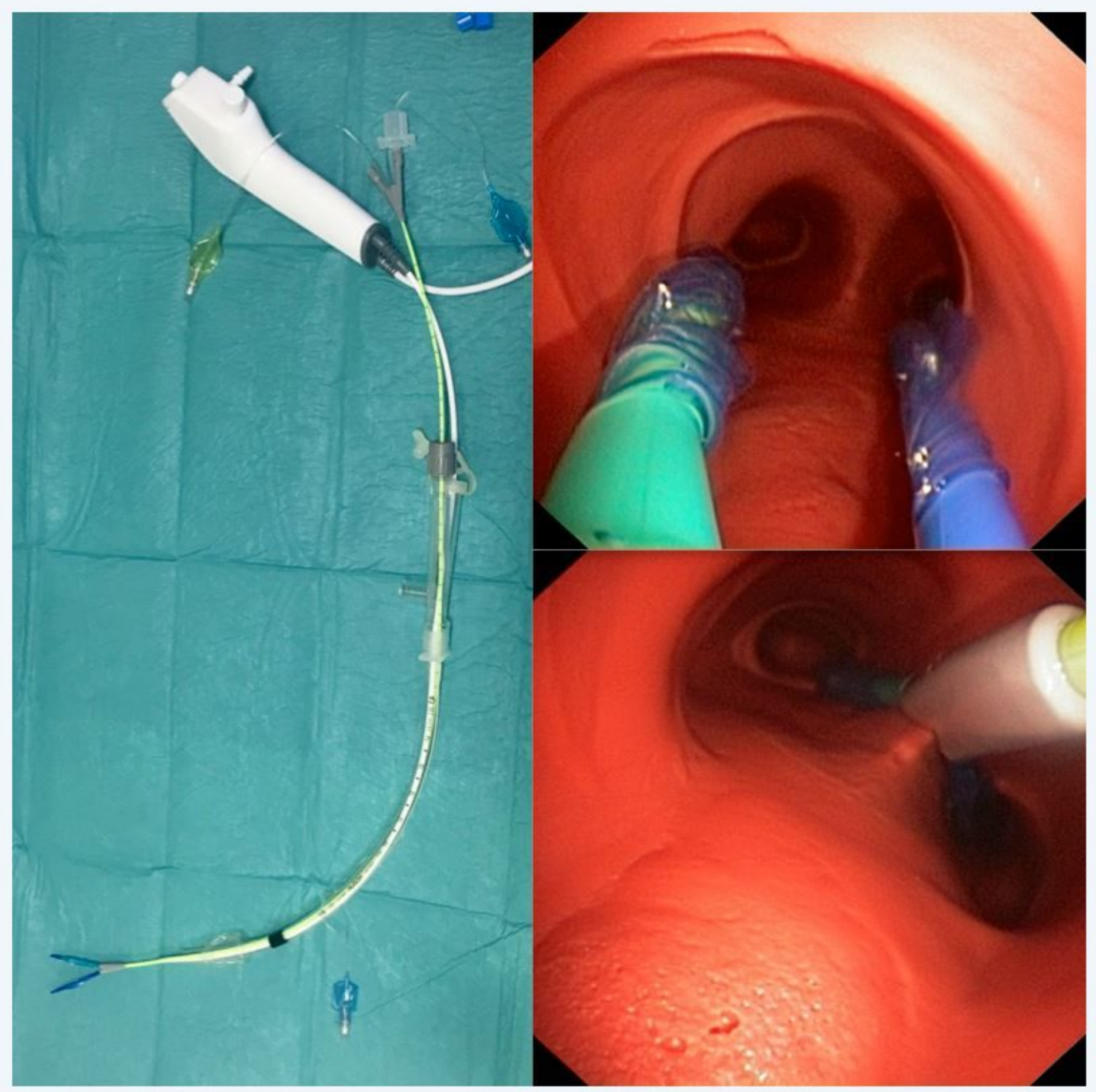

Figure 1

EZ-Blocker and bronchoscope. a. EZ-Blocker (EZB) and Ambuß Broncho aScope 4 slim 3.8/1.2placedthrough a single-lumen tube (SLT) $7.5 \mathrm{~mm}$, b. View with the Ambu ${ }^{\circledR}$ Broncho aScope 4 slim 3.8/1.2on the main carina and c. firm y-shaped position of EZB on the main carina. 


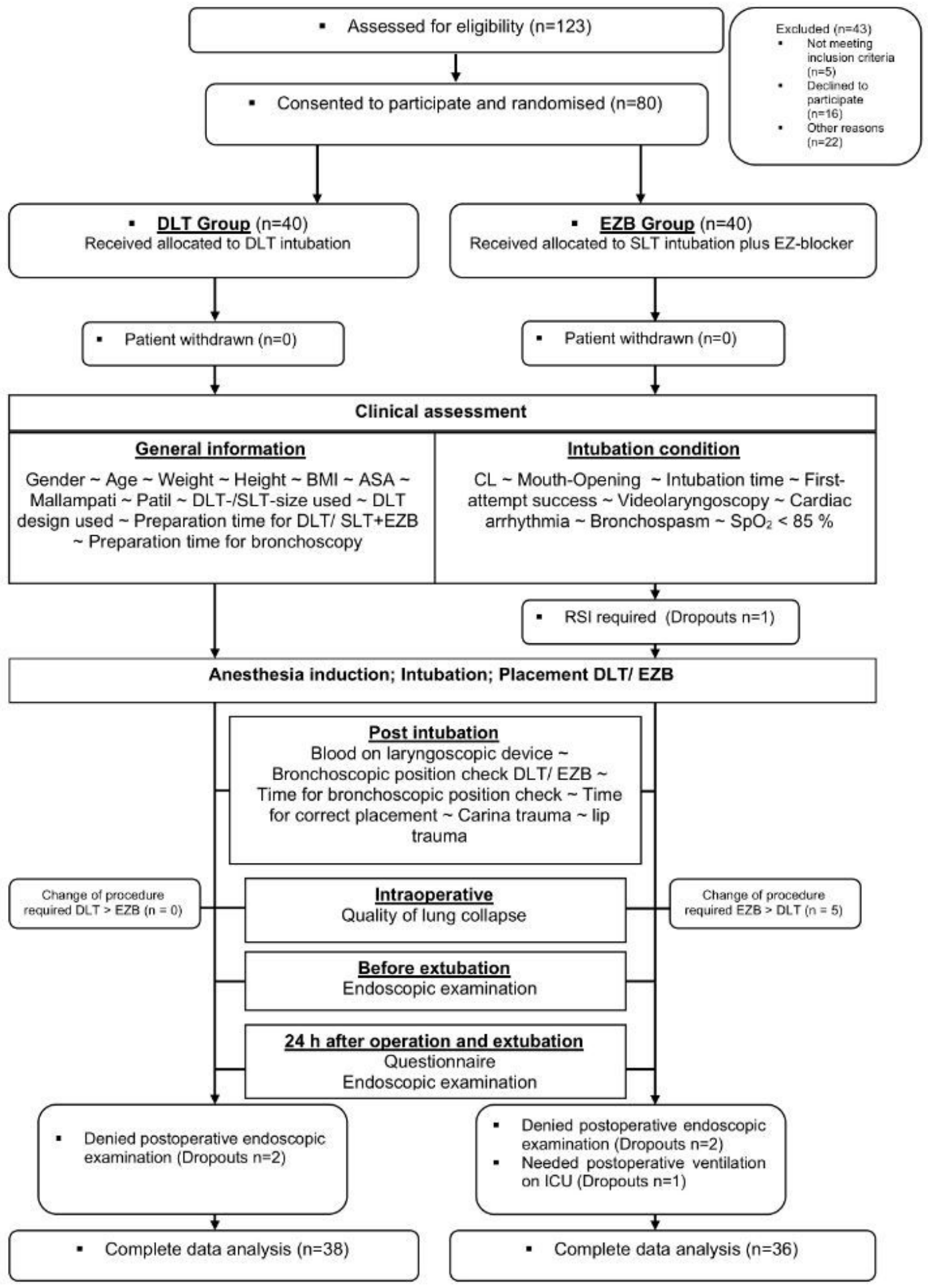

\section{Figure 2}

CONSORT and study flow diagram. 


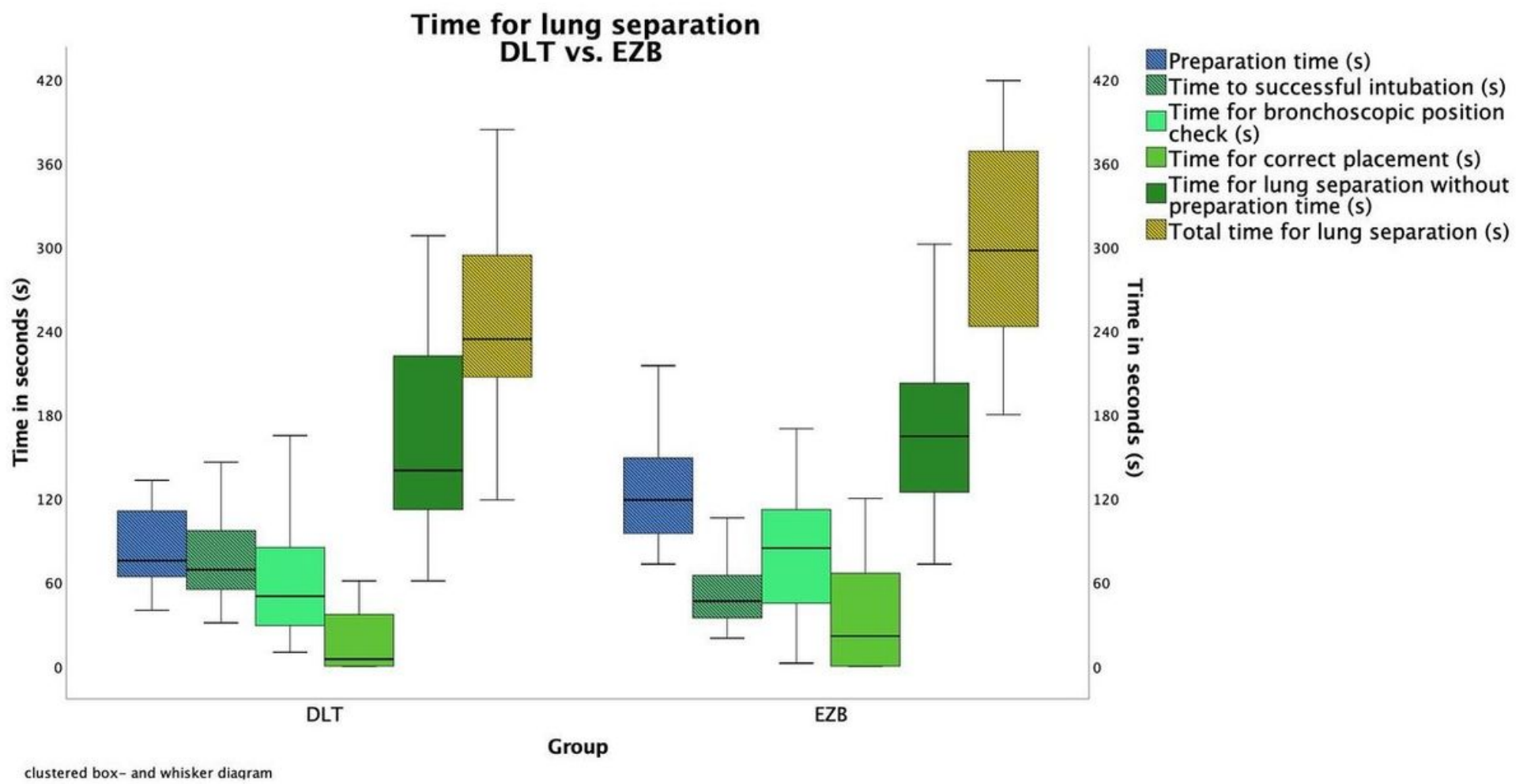

\section{Figure 3}

Clustered box-and-whisker diagram of process times for lung separation. 


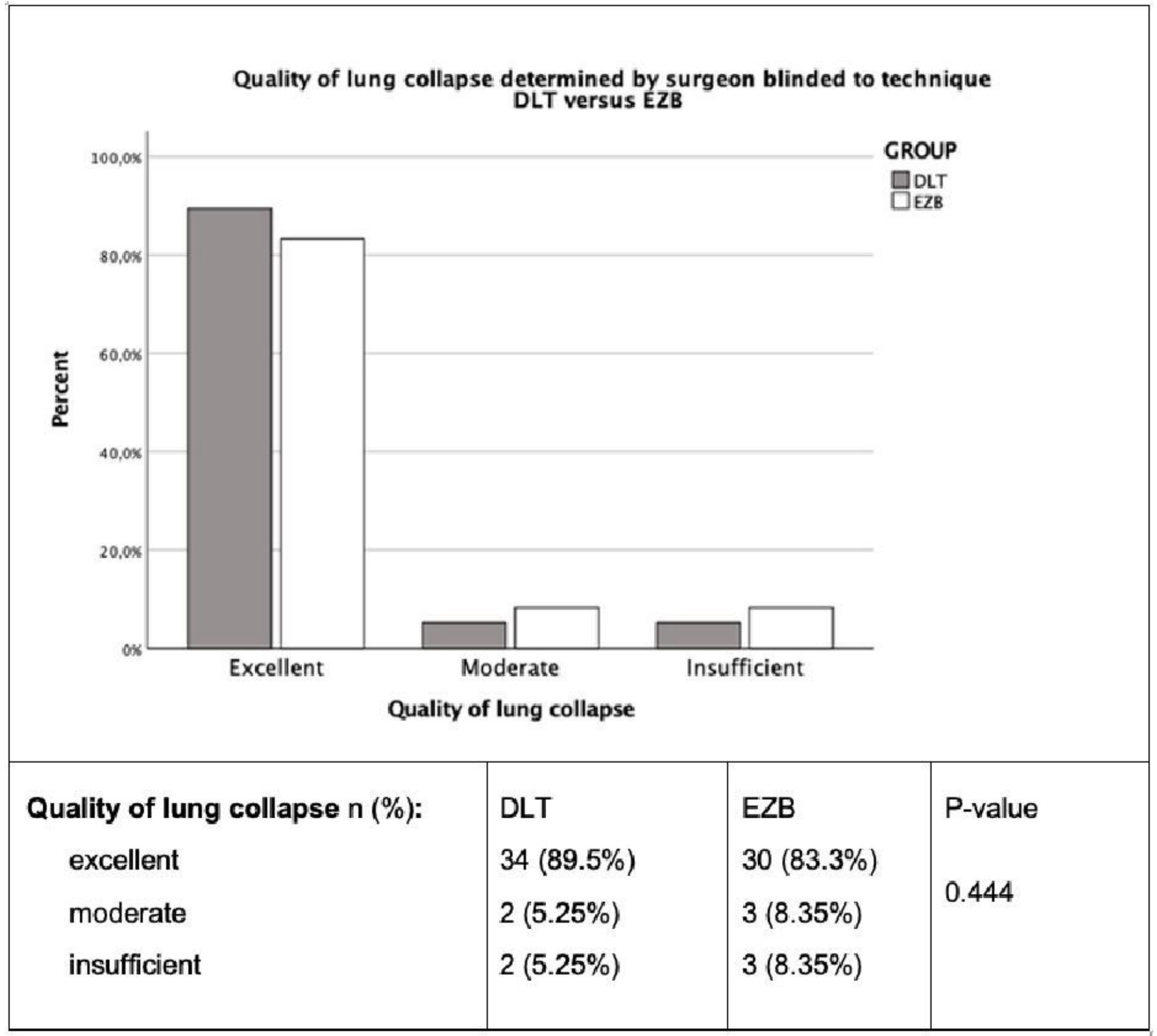

Figure 4

Bar chart and results of the quality of lung collapse. 